\title{
A SERICICULTURA NO ESTADO DE SÃO PAULO
}

(Alguns dados atuais e possibilidades futuras) (*).

\author{
MARIA REGINA DA CUNHA RODRIGUES \\ Assistente de História Ibérica da Faculdade de \\ Fllosofia, Ciências e Letras da Universidade de \\ São Paulo.
}

Considerando que tanto no Oriente como no Ocidente, o fornecimento do fio de sêda preocupa os responsáveis por essa milenar fonte de beleza e de lucro - justifica-se que à pauta do II Simpósio Brasil-Japão, sejam trazidos alguns problemas para a reflexão em comum. Cumpre deixar bem claro que se trata de dados parcelados, apenas do Estado de São Paulo, por duas razões: nos outros Estados brasileiros, ao que se sabe, a produção é quase inexistente. Ao passo que São Paulo, conta com um Serviço de Sericicultura (Departamento da Secretaria de Agricultura do Estado de S. Paulo), do mais alto nível - cuja constatação é pacífica àquêles que visitam suas instalações ino município de Campinas, distante apenas $96 \mathrm{kms}$ da capital paulista. Além de uma excelente documentação catalogada em seus arquivos, há outro fator preponderante. Esse Serviço é, no gênero, o único que se isabe existir em todo o continente americano.

Uma outra problemática provocada não pela própria repartição, mas pela premência do tempo determinado para a entrega destas notas. A área relacionada com essa cultura, cujo quadro estatístico transcrever-se-á mais adiante, parece coincidir com a de maior índice de imigração japonêsa. Todavia trata-se de mera conjectura a demandar uma pesquisa em profundidade, que precisará ser reconsiderada, pois os dados então conhecidos são inoperantes. De um lado,

(*). - Comunicação apresentada ao II Simpósio Brasil-Japão, realizado em Tóquio. Cf. Maria Regina e Eurípedes Simóes de Paula, Breve nota sôbre o II Colóquio Brasil-Japão (Tóquio, 29 de fevereiro-7 de março de 1968), in "Revista de História" no 73, pp. 165-172. (Nota da Redação). 
dos 41 municípios vinculados e relacionados pelo Serviço de Sericicultura, em outubro do ano passado, há nove nitidamente criados após o último levantamento estatístico que se conhece, que é o de 1965 (1). Do outro, a distribuição dos japonêses por região geográfica e, consequientemente por unidade municipal, que também se tem notícia, foca o ano de 1958 (2). Logo, a formulação de uma tese em que se relacionaria a produção de casulos e fios de sêda com a concentração de imigrantes japonêses em áreas especificadas, por ora, circunscreve-se ao campo das hipóteses problemáticas.

Contudo a distribuiçãoidos produtos segundo sua origem étnica, que também nos foi fornecida pelo Serviço, é a que se segue:

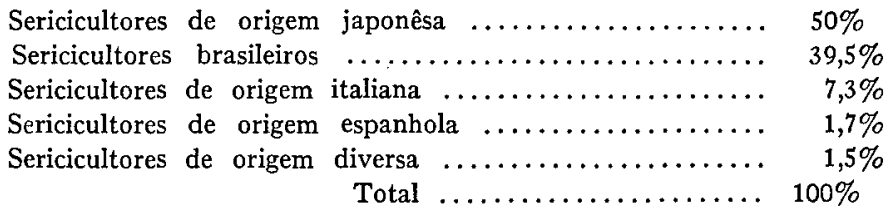

Uma outra consideração, passível de eventual solução positiva: o Japão passou, de maior exportador (3), a partir de maio de 1965, a importar fios de sêda, a fim de atender ao iseu consumo interno.

O Brasil, cognominado com propriedade de "país do futuro" (4), também nesta faixa, graças à sua extensa àrea territorial capaz de assegurar até 11 (onze) colheitas anuais (mais do dobro de outras áreas produtoras) e a operosidade de .seus técnicos vinculados ao Serviço acima mencionado, teria condições, estaria apto a concorrer pronta e decisivamente para o abastecimento, tanto das, indústrias nipônicas, como do Mercado Comum Europeu.

E o que se pode argumentar com a transcrição.de alguns dos dados enviados, oficialmente, ao Congresso Internacional de Sericicultura, que se realizou em Múrcia (Espanha) de 14 a 18 de novembro de 1967.

Em resposta à circular recebida e dada a impossibilidade de uma participação pessoal, o diretor do Serviço de Sericicultura enviou, por intermédio do adido comercial da Embaixada do Brasil

\footnotetext{
(1). - Govêrno do Estado de Sáo Paulo - Secretaria de Economia e Planejamento - Departamento de Estatística - Noticiario Estatístico (Setor de Relaçóes Públicas). Săo Paulo, pp. 3/14 - 1967.

(2) . - The Japanese Immigrant in Brazil (Comissão de Recenseamento da Colônia Japonêsa). Săo Paulo, Brasil.

(3). - Scarpelli (Ermelindo). Tokyo., pp. 5/21 - 1964.

(4). - Zweig (Stefan)., Brasil, país do futuro (tradução de Odilon Gallotti). Rio de Janeiro, Editôra Guanabara, 1941.
} 
em Madrí, uma expressiva ,comunicação, de cuja cópia, com a devida vênia, transcrever-se-á o que se segue:

$$
\begin{aligned}
& \text { “... Total da área cultivada (Estado de São Paulo) }-6.895 .179 \\
& \text { hectares. } \\
& \text { número de pés de amoreira .. 34.475.500 } \\
& \text { produção da última safra }(1966 / 67)-146.899 .066 \text { quilos }
\end{aligned}
$$

Estimativas para os próximos 10 anos:

$$
\begin{aligned}
& \text { “.. elevar a área cultivada de } 6.895 .79 \text { hectares para } 25.000 \\
& \text { hectares; com um total previsto de } 250.000 .000 \text {. pés de amoreiras, } \\
& \text { para uma produção de } 10.000 .000 \text { de quilos de casulos verdes e, } \\
& \text { conseqüenternente para uma produção de } 1.120 .000 \text { quilos de fios, } \\
& \text { que na cotação de } 16 \text { dólares por quilo, daria um total de } 17 . \\
& 920.000 \text { dólares anuais". }
\end{aligned}
$$

Êsses cálculos são, como não poderia deixar de ser, alicerçados em dados rigorosamente científicos. Todavia, cumpre deixar bem claro que êsse projeto depende e muito, de uma autêntica política governamental, através de seus setores administrativos, cuja sensibilidade precisaria ser despertada através de um plano racional e ef:tivo de financiamento, no sentido de implantação de novas culturas de amoreiras e de revisão dos equipamentos, tanto das sirgarias, como das incubadeiras.

Dir-se-ia que diálogos, tanto com autoridades governamentais, como com particulares, provocados em encontros internacionais como o que ora se realiza na "Capital da Sêda", poderiam valer de ponto de partida, para a concretização de acôrdo, na área da sua especialidade. Pois, ontem como hoje, os ; historiadores constituem ou poderiam constituir uma fôrça ponderável, decisiva quase, um brado de alerta aos responsáveis pelo bem-estar comum.

Ainda mais quando se poderia apresentar uma outra consideração de ordem sócio-econômica a impressionar, eventualmente, os sericicultores. Sugerida pela oportunidade dos dados levantados recentemente pelo ministro das finanças da França, Mr. Olivier Guichard quem, numa análise lúcida, veiculada no nosso país (5), calcula em $6 \%$ o aumento anual do consumo de artigos de sêda. E, ao mesmo tempo, dá os índices da atual produção de fibras texteis calculando em: ,

"97 para o algodão, 166 para a sêda e 210 para as fibras artificiais e sintéticas".

(5). - Scarpellt (Ermelindo)., ibidem. 
E o eng. Scarpelli argumenta:

“... as fibras sintéticas tiveram o seu consumo aumentado, em detrimento do algodão, que caiu verticalmente e não a sêda, como se poderia supor, a qual mantem sensivel ritmo de crescimento".

Poder-se-ia explicar essa possibilidade até, como fator sociológico, ponderando que, se no passado a sêda, objeto de luxo, foi um tecido usado por uma classe previlegiada, pela elite, pelos ricos, hoje com o desenvolvimento tecnológico, acompanha o alargamento do setor terciário.

E o que se verifica pelo acesso aos altos cargos administrativos, tanto na política, como nas emprêsas comerciais, de um número crescente de indivíduos, tanto homens como mulheres. Esta ascensão, somada ao gôsto pelo luxo e aceitação da moda, permitem antever não só a manutenção como também o aumento do consumo da sêda ${ }_{i}$ por longo período, ao lado das fibras sintéticas. Conseqüentemente as perspectivas comerciais dêsse mercado são as mais tranqüilizadoras. Fechando êsse parêntesis, cujo único objetivo vincula-se ao fato de se formar a lado,daqueles que reconhecem que o historiador é um homem do presente e que precisa sentir a problemática de sua própria época, é que, tendo em mente a situação atual, conhecida, da sericicultura japonêsa e as possibilidades da sericicultura brasileira, iremos armar nossa exposição com dados oficiais balisando-a no, plano seguinte:

I. - Breve notícia histórica.

II. - Produção anual de casulos e fios de sêda, dos anos sericícolas de 1963/64 e 1967.

III. - Levantamento da área cultivada nos anos de 1963/ 64 a 1967.

IV. - Distribuiçạ̃o da atividade sericícola em 41 municípios paulistas.

V. - Produção dos ovos de sirgo nos anos de 1963/64 a 1967.

VI. - Rendimento econômico nos anos de 1963/64 a 1967.

- Conclusões.

- Fontes consultadas.

\section{I - Breve notícia histórica.}

Cabe à iniciativa particular a prioridade de haver introduzido a sericicultura no estado de.São Paulo. Pois foi no ano comemorativo do 1 ọ centenário da independência do Brasil, em 1922 que um grupo de capitalistas fez surgir no município de Campinas, a " $S / A$ Indústria de Sêda Natural". 
Justifica-se destacar que um dos associados, ,o dr. Luís Pereira Tavares, era descendente direto do pioneiro da sericicultura brasileira, o benemérito José Pereira Tavares, autor de uma valiosa memória:(6), da qual ainda hoje existem raros exemplares. Com base nessa fonte primária pode-se admitir que o berço da criação de casulos e produção de fios de sêda, no Brasil, ocorreu em Itaguahy, na então Província do ;Rio de Janeiro, chamada também Província Fluminense, precisamente num ano de grande significação histórica para o mundo ocidental: 1848. Narra o (7) presidente-criador do Instituto Sericicola de Itaguahy que, ante a eminência de um colapso financeiro, solicitou e conseguiu numa audiência aos 26 de novembro de 1852, que o Imperador do Brasil, D. Pedro, II se interessasse pela novel indústria.

Interêsse que se concretizou, não sòmente, numa demorada visita à sede do Instituto, realizada aos 12 de dezembro de 1852, mas na criação da "Imperial Companhia Seropédica Fluminense" da qual o,Imperador acedeu em ser o acionista $n^{\circ} 1$.

Assim o grande Imperador Brasileiro (8) situa-se na mesma faixa dos mais altos dignatários do Extremo Oriente e da Europa Meridional que sempre souberam prestigiar a sericicultura em seus domínios.

\footnotetext{
(6). - Tavares (José Perelra)., Memória sóbre a sericicultura no Império do Brasil, Rio de Janefro.

(7) . - Tavares (José Pereira)., op. cit., pg. 151.

(7). - Tavares (José Pereira)., op. cit, pg. 151.

(8). - A história do Brasil apresenta uma particularidade no contexto da história do continente americano. Havendo sido descoberto por um capitáomor português, aos 22 de abril de 1500 fol, como é óbvio, colônia de Portugal até a proclamaçăo de sua independêncla, aos 7 de setembro de 1822. Todavia, com a invasão de Portugal pelas tropas de Napoleáo Bonaparte, a Familia Real Portuguêsa transmigrou-se para o Brasil. De 1808 a 1821, a Côrte ficou no Brasil atê que o reí $D$. João vI pudesse voltar a relnar em Portugal. Regressou e detxou como Príncipe-Regente, seu filho primogênito, D. Pedro casado com a arquiduquesa D. Leopoldina de Habsburgo. D. Pedro rebelou-se contra sua própria pátria đe nascimento, uniu-se aos brasileiros e proclamou a independêncla do Brasil, sob a forma de Império, sendo êle coroado seu 18 Imperador. Sucedeu-lhe em 1831, seu úntco filho varão, que pelo lado materno era neto do Imperador da Áustria. D. Pedro, que nasceu no Rto de Janeiro, aos 2-XII-1825 e faleceu em Paris, aos 5-XII-1891, fol coroado com o nome de D. Pedro II. Governou o pais durante mals de meio século. Lamentàvelmente năo teve filhos varóes, apezar de amado pelo povo, fol deposto numa revolução sem derramamento de sangue em 1889 e partiu para a Europa, onde morreu, dois anos depois. Assim é que desde 15-XI-1889 o Brasil, passou de Império a uma República Federativa Democrática, sendo seu atual presidente, o Marechal Artur da Costa e Silva que recentemente realizou uma visita oficial a êste fabuloso país. Oportunidade em que fol agraciado com o título de Doutor Honoris Causa pela Universidade para Estrangelros de Kyoto, fundada e dirigida pelo casal Morita e que, entre os seus professôres há um sóclo correspondente da nossa Sociedade de Estudos Históricos, o Sr. Faust Cardona, que também exerce o cargo de Cônsul Geral do Brasil, em Kobe.
} 
Todavia uma série de fatôres a que, não cabe aqui enunciar derrotou o esfôrço dessa equipe pioneira.

Mas a semente fôra lançada à terra e, anos mais tarde, poude germinar e florescer da maneira hoje irreversível, no Serviço de Sericicultura de Campinas.

Em se tratando de uma informação dé ordem histórica, justifica-se concatenar alguns dos dados, referentes à sericicultura no Brasil, já :na época republicana:

1908. - Em consequiência da posição tomada pelo Deputado Federal José Bonifácio de Andrada e Silva, foi promulgada a Lei , no 2050 de 31-XII-1908, extendendo à sericicultura os favores consignados nas instruções baixadas com o dec. no 6.519 de 13-VI-1907.

1912. - Foi criado, pelo dec. $\mathrm{n}^{\mathbf{0}} 9671$ de,10-VII-1907 a Esta ção Sericícola de Barbacena (Minas Gerais) provàvelmente o $1^{\text {o }}$ estabelecimento brasileiro oficial no gênero (9) .

1922. - Conforme já se registrou no início, instalou-se em Campinas (São Paulo) a "S/A Indústria da Sêda Natural".

1935. - Entre as realizações marcantes do período governamental de Armando de Salles Oliveira, situa-se a criação do $1^{\text {o }}$ órgão oficial da sericicultura no estado de São Paulo, em Campinas, que passou a constituir a $3^{\text {a }}$ secção do Departamento de Indústria Animal da Secretaria da Agricultura, Indústria e Comércio.

Instalado no próprio município de Campinas pelo Ato de 6 de julho de 1935, teve como 1 o diretor o $\mathrm{Dr}$. Francisco Assis Iglésias, que anteriormente havia exercido a gerência da "S/A Indústria de Sêda Natural".

1937. - Tendo como propositora a Deputada Maria Teresa de Barros Camargo, o projeto-lei de 19-I-1937 criou a .Estação Experimental de Sericicultura, no município de Limeira.

1941/42. - No govêrno do grande Fernando Costa, a sericicultura paulista conheceu seu período áureo pois, de ,uma

(9). - Apesar de figurar o municipio de Barbacena em quadros de "Produção de casulos, segundo regibes fisicgráficas das unidades da Federaçáo" (como ocorre com o Serviço Estatístico de Produção do Ministério da Agricuitura, de 1966) prova-se e comprova-se que em Barbacena somente existe uma estação experimental. Assim como no $\mathrm{km} 40$ da Estrada Rio-Sāo Paulo (no ENA - Escola Nacional de Agricultura) no Estado co Río de Janeiro), apenas estação, sem interêsse comercial e sintonizadas ambas com o Serviço de Sericicultura de Camplnas. 
só fiação passou num ano a contar com 40 fiações. Por ato do governador F. Costa, a $3^{a}$ secção foi transformada devido a sua especialidade em secção autônoma, com nome de Serviço de Sericicultura da Secretaria da Agricultura. Ocupa uma vasta área na Alameda das Amoreiras $n^{\circ} 165$, onde se encontram instalados os diferentes órgãos de pesquisa e de administração, assim como residências de funcionários e de seu atual diretor.

Na direção desse Serviço está, desde 2-I-1964, o enge. agrônomo Ermelino Scarpelli, que lhe vem dando autêntica dinamização, „projetando-o dentro e fora do país .

E o que se pode verificar através da correspondência arquivada como do registro de visitantes, dentre os quais altos funcionários do govêrno e das indústrias sericícolas daqui e do Japão .

Antes da transcrição dos quadros estatísticos manipulados por essa modelar repartição pública, impõem-se alguns esclarecimentos àquêles que não .estão familiarizados com essa atividade humana:

1) . - O ano siricícola compreende o período de 1 de outubro a 30 de setembro.

2). - Os dados abaixo transcritos „referem-se a casulos verdes.

3). - O levantamento realizado foi de acôrdo com o sistema que vem sendo mantido, no Serviço e que o seu próprio diretor argumenta haver sido feito: “... diretamente na fonte, conforme fichas individuais em poder dêsse Serviço. Não foi adotado o „processo de amostragem (11).

Fato que, além de garantir tranquiilidade e segurança aos pesquisadores, .poderia servir como norma aos manipuladores de dados estatísticos, isto é, informar o tipo de processo adotado e, sempre que possível, colher dados na própria fonte.

Ainda, nestas notas preliminares, ,limitar-se-a a transcrição dos quadros fornecidos pelo Serviço, sem uma análise dos mesmos que, por ora, não se justificaria.

\footnotetext{
(10). - São Paulo, Paláclo do Govêrno - Medidas preliminares, paz interna, pessoal habilitado e finanças sólidas e bem equilibradas - Sáo Paulo, Imprensa Oficial (A Sericicultura, pp. 61-64) .

(11). - Scarpelli (Ermelindo)., Relatório, ibidem.
} 


\section{II. ._- Produção anual}

Produção anual de casulos e fios de sêda dos anos siricicolas de 1963/1967 (12).

\begin{tabular}{cr}
\hline Anos Siricícolas & \multicolumn{1}{c}{ Casulos } \\
& \\
$1963 / 64$ & $713.812,716$ \\
$1964 / 65$ & $932.202,880$ \\
$1965 / 66$ & $1.114 .794,190$ \\
$1966 / 67$ & $1.313 .467,740$ \\
\hline
\end{tabular}

III. - Levantamento da área cultivada nos anos de 1964/67 (13).

\begin{tabular}{cccc}
\hline Ano & Área/Alq. & $\mathrm{N}^{\circ}$ pés amoreiras & $N^{\circ}$ sirgaria \\
\hline 1964 & $1.402,5$ & 13.453 .000 & 463 \\
1965 & $2.046,5$ & 18.802 .000 & 648 \\
1966 & $2.641,5$ & 31.071 .000 & 923 \\
1967 & $2.849,5$ & 34.479 .500 & 1.023 \\
\hline
\end{tabular}

IV. - Distribuição da atividade siricícola em 41 municipios (14).

A não ser por razões didáticas não se precisaria alertar que a ordem seguida focaliza os municípios em razão da ,produtividade decrescente:

Localidade Area/alq. $\quad n^{0}$ pés amoreiras $N^{Q}$ de sirgarias

$\begin{array}{lrrr}\text { Gália } & 648,5 & 10.118 .300 & 253 \\ \text { Duartina } & 391,5 & 5.872 .300 & 135 \\ \text { Avaí } & 309,0 & 3.551 .000 & 100 \\ \text { Lucianńpolis } & 161,0 & 2.272 .000 & 84 \\ \text { Bastos } & 285,5 & 2.216 .500 & 80 \\ \text { Baurú } & 196,5 & 1.861 .000 & 53 \\ \text { Tibiriçá } & 135,0 & 1.474 .000 & 43 \\ \text { Piratininga } & 79,5 & 1.080 .000 & 33 \\ \text { Agudos } & 45,0 & 676.000 & 20 \\ \text { Cabrália Pl. } & 44,5 & 540.000 & 14\end{array}$

(12) . - Dados tirados do Quadro I que acompanha o relatório enviado pelo diretor do Serviço de Sericicuitura ao Diretor da Divisăo de Economia Rural do Estado de São Paulo, aos 10-X-1967.

(13). - Ibidem.

(14). - Ibidem. 
Guatá-João Ramalho

$\begin{array}{rrr}100,0 & 505.000 & 18 \\ 51,0 & 502.000 & 26 \\ 47,0 & 493.000 & 25 \\ 29,5 & 337.000 & 13 \\ 34,5 & 305.900 & 15 \\ 39,0 & 270.000 & 14 \\ 24,5 & 266.000 & 9 \\ 34,5 & 262.000 & 9 \\ 21,0 & 232.000 & 5 \\ 21,5 & 218.000 & 12 \\ 17,5 & 210.000 & 5 \\ 19,5 & 204.000 & 6 \\ 21,0 & 197.000 & 16 \\ 17,0 & 177.000 & 5 \\ 12,0 & 144.000 & 4 \\ 9,0 & 80.000 & 7 \\ 9,0 & 72.000 & 3 \\ 7,0 & 67.000 & 7 \\ 5,0 & 60.000 & 2 \\ 5,0 & 60.000 & 2 \\ 4,0 & 48.000 & 1 \\ 3,0 & 30.000 & 1 \\ 3,0 & 30.000 & - \\ 2,5 & 25.000 & 1 \\ 3,0 & 24.000 & 1 \\ 4,0 & 24.000 & 2 \\ 4,0 & 24.000 & - \\ 2,0 & 16.000 & - \\ 2,0 & 12.000 & 1 \\ 1,0 & 6.000 & \end{array}$

Promissão

Guatapará

Guaimbé

Mirandópolis

Rosália

Charqueada

Oswaldo Cruz

Indaiatuba

Tangará

Itatiba

Espirito Santo do Turvo

Mococa

Iacrí

Vera Cruz

Guaçara

Inúbia

Dracena

Getulina

Paulicéa

Nogueira

Guaraçaí

Eng. Coelho

Motuca

Pereira Barreto

São Carlos

Ibitinga

Tambaú

Itirapena

Aparecidinha-Campinas

Area/Alq.

$N^{O}$ pés amoreiras

$N^{Q}$ de Sirgarias

Presidente Prudente

TOTAL

0,5
$2.849,5$

1.500

34.475 .500

1.023

V. - Produção dos ovos de sirgo nos últimos 4 anos (15).

$\begin{array}{clll}\text { Safra } & \text { Serviço de - } & \text { Institutos } & \text { Totais em Gramas } \\ & \text { Sericicultura } & \text { Particulares } & \end{array}$

\begin{tabular}{rrrr}
\hline $1963 / 64$ & $87.641,4$ & $251.645,0$ & $339.286,4$ \\
$1964 / 65$ & $94.280,5$ & $261.215,0$ & $355.495,5$ \\
$1965 / 66$ & $87.793,0$ & $350.881,0$ & $438.674,0$ \\
$1966 / 67$ & $146.316,0$ & $442.501,0$ & $538.817,0$ \\
\hline
\end{tabular}

(15). - Ibidem. Presentemente, existem três institutos particulares produzindo ovos de strgo, sendo, dols em Bastos e um em Lins. 


\begin{tabular}{ccccc} 
Ano siricícola & $\begin{array}{c}\text { NCr\$ } \\
\text { Casulos }\end{array}$ & preço médio & $\begin{array}{c}\mathrm{Kg} \\
\text { Fio de sêda }\end{array}$ & $\begin{array}{c}\text { Industrial } \\
\text { Renda }\end{array}$ \\
\hline $1963 / 64$ & $672.115,23$ & 0,94 & $88.637,736$ & 8.299 \\
$1964 / 65$ & $1.570 .523,99$ & 1,68 & $111.844,989$ & 8.000 \\
$1965 / 66$ & $2.356 .626,96$ & 2,11 & $134.598,813$ & 8.140 \\
$1966 / 67$ & $3.642 .464,67$ & 2,77 & $146.899,066$ & 7.955 \\
\hline
\end{tabular}

\section{CONCLUSÕES.}

Parece ponto pacífico a inexistência, por ora, de uma história da sericicultura no Brasil.

Todavia no estado de São Paulo, no município de Campinas há um Serviço de Sericicultura oficial, pois está vinculado à Secretaria da Agricultura, que consta ser o único do, continente americano.

Essa repartição conta, além de instalações modernas, pessoal do mais alto nível técnico e científico, tendo à frente, o eng. agr. Ermelindo Scarpelli.

Fato que, aliado às condições favoráveis de uma vasta área territorial capaz de facultar até 11 (onze) colheitas anuais de casulos - recorde absoluto pois outras áreas produtoras do mundo, não conseguem mais de 5 colheitas anuais - Poderia, alicerçado num autêntico apôio do govêrno, e, de acôrdo com estimativa das fontes autorizadas, conseguir aumento da produção de fio de 146.899,066 quilos, para $1.120,000$ quilos que na cotação de 16 dólares por quilo, daria um total de US\$17.920,000 anuais.

Possibilidade que facultaria ao Brasil concorrer e muito para o abastecimento de fios de sêda, do Mercado Internacional, especificamente do Japão que, ao que sabe, de país maior produtor passou, desde setembro de 1966 a importar o produto de outras áreas.

Justifica-se realçar que essa atividade sericícola, que foi introduzida em nosso país em 1848, com o apoio do Imperador do Brasil, D. Pedro II, limita-se hoje a áreas específicas do estado de São Paulo, onde $50 \%$ dos sericicultores são de origem japonêsa.

(16). - Ibidem. O preço médio acima, segundo informaçóes do Diretor do Serviço de Sericicultura, é correspondente à compra do casulo verde, sendo que, de janeiro ao fim da safra, as fiaçóes descontaram do lavrador - I.C.M. (Imposto de Circulaçáo de Mercadorias). 
IGLESIAS (Francisco de, Assis)., A Sericicultura no Brasil., in "Sericicultura Boletim da Secretaria da Agricultura, Indústria e Comércio do Estado de São Paulo - Diretoria de Publicidade Agrícola". São Paulo, pags. 15/74.

- A Sêda, sob o aspecto econômico, pode ter o valor do algodão $e$ da Laranja. in "periódico Fôlha da Manhã" (Sucursal de Campinas) São Paulo, 14 de agôsto de 1938.

Comissão de Recenseamento da Colônia Japonêsa. The Japanes Immigrant in Brazil. Tokyo, The University of Tokyo Press, Bunkyo, - Ku, 1964.

Rio de Janziro. Ministério da Agricultura. Produção de casulos, segundo as regiōes fisiográficas e as unidades da Federação, 1963/65. in "Serviço de Estatística da Produção, - Departamento Econômico" Rio de Janeiro, Dezembro de 1966.

São Paulo - Palácio do Govêrno - A Sericicultura. in "Medidas preliminares: paz interna, pessoal habilitado e finanças sólidas e bem equilibradas". São Paulo, pgs. 61/64. - 1943.

São Paulo, Secretaria de Economia e Planejamento - Departamento de Estatística - Estimativas Populacionais, por município - (1964-1965). in "Noticiário Estatístico I - Setor de Relações Públicas". São Paulo, pgs. 3/14 - 1967.

SCARPELLI (Ermelindo).,. Cópia do relatório datado de: Campinas, 10 de outubro de 1967, protocolado sob $\mathrm{n}^{\mathrm{g}} 1.114$ e enviado ao Dr. Constantino Carneiro Fraga, diretor da Divisão de Economia Rural da Secretaria da Agricultura do Estado de São Paulo.

- Situação Internacional da Sêda., (artigo inédito datado de Campinas, 19 de dezembro de 1967).

TAVARES (José Pereira)., Memória sôbre a Sericicultura no Império do Brasil. Rio de Janeiro, Typographia Imperial e Constitucional de J. Villeneuve, 1860. 